\title{
Study on Optimization of Construction Management of Large Project
}

\author{
Chenghua Guo \\ Liaoning Jianzhu Vocational College, Liaoyang, Liaoning, 111000
}

\begin{abstract}
At present, China's engineering contractor management philosophy and management methods and world-class large-scale project contractors have a great gap. How to deal with the challenges of high level contractors abroad, how to further explore the international engineering contracting market, improve the overall competitiveness of China's engineering contracting enterprises in the international engineering market, improve the economic benefits of contracted projects, is becoming an urgent problem for our contractors to solve.
\end{abstract}

Keywords: Large Project, Construction Management, Optimization Technology

\section{Introduction}

Large-scale construction plan as a contractor for the project management and an important basis for the text, the contractor's daily construction and management plays a guiding role in the forward-looking. The management optimization of cost-based construction plans for large-scale construction projects will help the contractors to achieve the targets set by the project, improve the construction management level of the project contractors, and save the construction and management costs, so as to improve the contractor's projects Competitiveness and the economic benefits of contracting projects. At present, the study of large-scale project construction scheme is fragmented, lack of systematic analysis, and largescale projects with the characteristics of the combination is not enough. And the research cannot adapt to the actual construction needs, the lack of practical significance of the contractor's work. In the actual construction process, the contractor based on the construction program, the construction project objectives 
to control. Once the indicators of the construction plan out of reality, the lack of the content of the implementation of the program to guide the implementation of indicators, will make the program indicators, especially the cost indicators in the construction phase is out of control. The loss of the project can not be made up. Thus, the formulation and optimization of construction projects for the entire large-scale project management has an important role, it will certainly be the future of project management optimization of the direction and focus.

\section{Overall construction project of large-scale project evaluation index system}

In the optimization of the construction plan of the large-scale project, the cost index is the focus of the contractor's attention. The contractor in the construction program the most important content) construction technology program, the general layout and site transportation, project resource management, the program should focus on cost control, and should be combined with progress, quality and safety management to ensure that the project The realization of comprehensive goals.

In the design of the overall evaluation index system, the contractor should reflect the progress, quality, safety and cost index of the project, especially the cost index. The cost index should be emphasized in the design of the index weight to highlight the cost optimization of the construction plan. purpose. In determining the evaluation index of the project, the contractor shall, in accordance with the characteristics of the large-scale project, use the questionnaire, causal analysis and other methods to determine the main factors affecting the construction. On the basis of factor analysis, the paper summarizes and classifies, and chooses and focuses on the final index level and specific indicators. For large-scale projects, the single project construction, site layout and site transportation, project resource management is the contractor in the construction progress control, quality, safety and cost of the most important way, but also the construction of the project can be the most successful Important aspects of the impact. Therefore, the contractor in the construction program overall evaluation index system design, should start from the above three aspects, analyze the impact factors, refine the specific indicators.

Contractors to conduct a single project are based on the construction of technical solutions. The cost, duration, quality and safety of single project construction are the most important evaluation indexes in the project construction technology. Meanwhile, the difficulty in construction, the coordination ability, the relationship between the construction and the whole project and other single projects should be considered. Factor is to determine the indicators. In a largescale equipment installation, equipment installation should also consider the factors affecting the determination of the corresponding indicators. The layout of the main temporary facilities and their impact on the overall construction are the most important considerations in the overall layout. The contractor shall determine the overall layout evaluation index from the aspects of cost, arrangement effect, environment, adjustment ability, etc. For some detailed 
layout problems, such as the position of scattered yard, In the single project construction technology program under consideration. Project resources are an important part of the contractor's cost control. The contractor should start from the main means of resource management, focusing on analysis of the impact of project costs and related factors. The key points are network resource planning, organization and management, procurement of major raw materials and equipment, and selection and determination of indicators and weights based on the correlation with project cost.

\section{Large-Scale Project Construction Program Optimization Method}

It is the core work of the project construction and management to determine the technical scheme of construction of single project. Contractor to determine the construction technology program for the cost and effectiveness of the project has a decisive role. The contractor should pay attention to the optimization of construction scheme, pay attention to the application of new technology and new method in construction, and reduce the construction cost.

Construction technology program mainly includes determining the construction method, selecting construction equipment, arranging construction organization and order.

1) to determine the construction method and process. The use of factory prefabricated or in the market purchase of finished or semi-finished products, reduces on-site production; the use of mechanized construction, reduce manual operations. The contractor shall, through technical and economic comparison, determine the construction method and process flow for the key segment project of the individual project. Such as deep foundation pit support structure, groundwater treatment methods, large span beam construction method choice. For the construction methods of the main types of work (such as pile foundation, structure installation, prestressed concrete works, etc.), the contractor shall, according to the construction specifications and technical regulations, make clear the technical measures for the project, determine the construction methods, improve production efficiency, Ensure project quality and construction safety, reduce project cost.

2) The choice of major construction machinery Contractor should be based on the construction site conditions and engineering structure, a reasonable choice of mechanical type and quantity. As much as possible to a machine, continuous use, in particular, large-scale machinery should be unified scheduling, centralized use. For the use of leasing in the form of machinery and equipment, contractors should strictly control the entry and exit time, in order to save the cost of machinery. The contractor should enable the performance of the leading machinery in each individual project to achieve integrated flow-shop operations, reduce its demolition, the number of transport; for auxiliary supporting machinery, its performance should be compatible with the leading construction machinery to fully play the leading construction machinery work effectiveness. 
3) Construction technology Organizational measures Construction technology Organizational measures are the methods and measures adopted by the contractor in the construction technical scheme for the four main objectives of the construction of the project. The Contractor shall, in the light of the main links of the unit construction and the specific conditions and conditions of the construction, proceed in accordance with the relevant statutes, regulations and construction experience.

The general layout of the construction site is very important for the realization of the construction scheme. Large-scale projects, a large number of construction facilities, between the various facilities will have mutual interference. As a result, the optimal or rational location of the individual arrangement may create a contradiction in the arrangement of a variety of facilities, and the contractor needs a comprehensive trade-off, a reasonable arrangement and an optimum adjustment of the site.

The general layout of the construction site is within the limited scope of the venue, selected feasible, optimal and reasonable location of the temporary facilities and road construction to meet the requirements of the construction. Generally speaking, in the general design and construction of the plane, the contractor should be the first site function division, the provision of temporary construction facilities, according to the layout of the situation of the facilities, the layout of the temporary construction site layout, Integrated layout of the temporary road and construction pipeline.

The layout of the construction site facilities can be considered as a small area planning around permanent buildings. The purpose of the planning is to provide reasonable accessory and temporary facilities for permanent building construction in a limited area and to provide accommodation for construction personnel, storage and storage of materials, construction and stopping of machinery, etc. by means of these ancillary and temporary facilities The required site. Therefore, the contractor's construction facilities should be the first venue function partition. According to the location of permanent buildings and construction sites inside and outside conditions, study the construction site of the division, zoning plan. Prefabricated factories, warehouses, houses, power supply, water supply and drainage pipelines and other construction facilities should be properly arranged in different functional areas so as to fully meet the construction intensity and progress requirements of the main projects and facilitate the construction and reduction of workers. Facilities cross-layout of the mutual interference, to ensure the safety of construction, environmental protection, reduces project costs. In the construction of large-scale projects, the contractor can be based on the impact of the main project construction and degree of dependence on the construction site level will be divided into: construction production area, construction and living area, construction auxiliary area.

Project resources refer to various factors that form productive forces, such as labor force, materials, equipment, capital, technology and so on. Large-scale construction projects require a lot of labor, materials, equipment, capital and technology, the cost of the project in general account for more than $80 \%$ of the total cost. Resource management optimization should follow the following 
principles: the minimum total resource consumption, rational use of resources, resources, investment in the construction of a balanced. Project resource management throughout the entire process of construction of the project, mainly reflected in the construction implementation stage. The resources required for the project on time and on demand, the quality and quantity of supply to the construction site, and a reasonable reduction of project resources consumption and reduce costs.

Large-scale projects require a wide range of resources, a huge number of resource constraints and resource constraints, resource demand is also uneven. Therefore, the resource plan must include the establishment of a comprehensive control program and responsibility system for the procurement, custody and use of all resources and the identification of plans for the supply and use of labor, materials and machinery. The resource plan plays an important role in the progress of the construction plan and the realization of the cost index. Construction technology program determines the demand for resources in a certain period of time, and as the construction of the overall network plan in the constraints of resources, the progress of the construction project has an important impact. At the same time, the balanced use of project resources.

\section{Conclusion}

The construction project of large-scale project is the basis for the contractor to bid for the project and the basis for the contractor to carry out the project construction and management. The quality of the construction plan is critical to the success of the contractor in achieving the project objectives. Therefore, the optimization of the construction plan for the contractor, not only the construction of the text modification and specification, but also the contractor in project construction and management of target control, an important means to achieve the project objectives.

\section{References}

[1] Chen Yixing. The Project Manager Responsibility System Construction Team [J]. Construction Economics, 2006 (11)

[2] Song Yang, Zhong DengHua. Multi-Resource Equilibrium Optimization Considering Time-Value of Capital [J]. Journal of Tianjin University. 2006 (09)

[3] Qi Zhaohui, Zhang Weihua, Fan Yuzhu. A New Weighting Method For Multiple Attribute Decision Making [J]. Operations Research and Management Science, 2008 (09)

[4] Liu Pengfei, Xie Ruhe. A Comparative Study of Modern Inventory Management Methods based on Supply Chain [J]. Business Research, 2006 (02)

[5] Fan Zhiqiang, Zhang Zhidong, Cheng Jinshi. Quantitative Research on Safety Inventory Considering Supply and Demand Volatility [J]. Logistics Science and Technology, 2005 (10) 